\title{
Supplement on health-related education, healing and sustainable development
}

We continued to receive submissions related to health-related education that could not all be accommodated in our November 2016 issue. To afford their timely publication, we present a supplementary issue enhanced by two conference reports and a book review.

Two original articles grace this issue. Training in clinical skills for medical students can be demanding of staff and teaching time, especially in settings where senior clinicians face competition for their time from their own practice and administrative duties. Dr. Cheryl Snyder and Rose Chisenga developed a training program for senior medical students who then taught clinical skills to fourth year students. This was followed up with an assessment that compared perceived preparedness and confidence levels with historical controls. The use of the senior students in peer-assisted learning significantly boosted the students' sense of preparedness and confidence as they began their fifth year clinical rotations.

The second original article is by Dr. Jeany

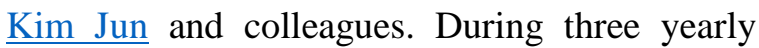
short term mission trips to Cambodia they collected data on the types of diseases seen and medications and diagnostic tests needed. This enabled them to prepare formularies and tests to more efficiently prepare for future trips with possible extension to other similar efforts.

The journal aspires to be a venue for open discussion of areas where global health practitioners might disagree. Consequently, we have published a submission from Dr. Mark Crouch who offered pushback on one of the November conference proceedings. Dr. Crouch argues for clinical practice having a continuing role in global health despite doubts regarding its sustainability. He notes that clinical experience is foundational for effective teaching in medically indigent areas because nothing in a Western medical education can prepare one for these types of challenges. His article is a vigorous riposte to the teaching-only cadre.

Two other articles round out the healthrelated education supplement. One documents a multi-disciplinary continuing education effort in Tanzania that provides a yearly conference focused on quality improvement. Dr. John Kvasnicka and colleagues explain how the conference is set up, run, and paid for and offer an evaluation of the most recent one in 2016, suggesting this may be a model that could be used in other contexts. Short term servicelearning continues to be popular for medical students, but there are pitfalls to be avoided. Kristen Sessions, supported by two of her mentors, describes her experience in Uganda tested against the existing literature and offers some very practical advice.

Global Health is an immense field of endeavor, and one way for the editors to stay abreast is to attend as many of the relevant conferences as possible. Dr. Daniel O'Neill attended a conference examining evidence for the role of faith in poverty reduction at Yale University last September, and reviews the interchanges between faith-based organizations and secular and government organizations. There appears to be movement towards greater recognition of the role of faith in development on the one hand, and recognition of a need for measurement and documentation on the part of faith-based organizations.

The second conference report is from the Christian Connections for International Health (CCIH) annual conference and is reported on by Kathy Erb in the current issue. $\mathrm{CCIH}$ is an 
organization that seeks to bring together Christians working across the public-private landscape. The 2016 theme was the relationship between Christian faith and sustainable development.

Last, but by no means least, is a review of Healing in the Gospel of Matthew: Reflections on Method and Ministry by Walter T. Wilson, submitted by Professor Brian Labosier.
Theological perspectives on health, healing, and wholeness are encouraged to frame global health approaches. The editors commission some reviews, but are often pleased to receive uncommissioned reviews relevant to our focus. Though we send calls for papers, we continue to seek submissions of any content. As you read please keep us in mind and send links of relevant articles to interested colleagues. 